\title{
FRAÇÕES DE FÓSFORO INORGÂNICO DO SOLO E SUAS CORRELAÇÕES COM O FÓSFORO QUANTIFICADO POR EXTRATORES E PELO MILHO(1)
}

\author{
Reginaldo Fidelis de Souza Júnior( ${ }^{(2)}$, Fábio Henrique Tavares de \\ Oliveira $^{(3)}$, Hemmannuella Costa Santos ${ }^{(4)}$, Fernando José Freire ${ }^{(5)} \&$ \\ Jandeilson Alves de Arruda ${ }^{(6)}$
}

\begin{abstract}
RESUMO
O fracionamento do fósforo inorgânico (Pi) do solo é importante para avaliar as formas com que ele está sorvido ao solo, pois a eficiência de um extrator de $P$ disponível depende da sua capacidade de extração de cada uma das frações de Pi do solo. Com este trabalho, objetivou-se avaliar os teores das frações de Pi em solos representativos do Estado da Paraíba e suas correlações com características químicas desses solos, bem como as correlações entre as frações de Pi e o P extraído dos solos por plantas de milho e pelos extratores Mehlich-1, Mehlich-3, Bray-1 e resina de troca iônica mista. O experimento foi realizado em casa de vegetação, no delineamento de blocos casualizados, com 12 solos, ausência e presença de $\mathrm{P}$, e três repetições. Após a aplicação das doses de $\mathbf{P}(75,88$ e $103 \mathrm{mg} \mathrm{dm}^{-3}$ ) nas amostras de $3,0 \mathrm{dm}^{-3}$ de solo, contidas em vasos de polietileno, elas foram incubadas durante três semanas com água destilada, na quantidade equivalente a $50 \%$ da porosidade total de cada solo. O P disponível extraído pelos quatro extratores químicos e o fracionamento do $\mathrm{Pi}$ foram determinados em subamostras de $0,2 \mathrm{dm}^{-3}$. As frações $\mathrm{P}-\mathrm{Al}$ e $\mathrm{P}-\mathrm{Fe}$ foram as que predominaram nos solos mais desenvolvidos e naqueles menos intemperizados com valores de $\mathrm{pH}$ e teores de $\mathrm{Ca}^{2+}$ mais baixos; já a fração $\mathrm{P}-\mathrm{Ca}$ foi predominante em solos alcalinos e com teores muito elevados de $\mathrm{Ca}^{2+}$. Acompanhando a tendência da planta, as
\end{abstract}

(1) Parte da Dissertação de Mestrado defendida pelo primeiro autor no Programa de Pós-Graduação em Manejo de Solo e Água, Universidade Federal da Paraíba - UFPB. Recebido para publicação em 4 de abril de 2011 e aprovado em 19 de outubro de 2011.

(2) Mestre em Manejo de Solo e Água, Departamento de Solos e Engenharia Rural, Centro de Ciências Agrárias, Universidade Federal da Paraíba - UFPB. CEP 58397-00 Areia (PB). E-mail: reginaldo_fidelis@hotmail.com

(3) Professor do Departamento de Ciências Ambientais e Tecnológicas da Universidade Federal Rural do Semi-Árido - UFERSA. CEP 59625-900 Mossoró (RN). Bolsista do CNPq. E-mail: fabio@ufersa.edu.br

(4) Professora do Departamento de Agropecuária, UFPB. Centro de Ciências Humanas, Sociais e Agrárias, Campus III, Universidade Federal da Paraíba - UFPB. CEP 58220-000 Bananeiras (PB). E-mail: hecosantos@yahoo.com.br

(5) Professor do Departamento de Agronomia da Universidade Federal Rural de Pernambuco - UFRPE. Recife (PE). Bolsista do CNPq. E-mail: f.freire@depa.ufrpe.br

(6) Doutorando em Solos e Nutrição de Plantas da Universidade Federal de Viçosa - UFV. CEP 36570-000 Viçosa (MG). E-mail: jandeilson_agro@hotmail.com 
formas de $\mathrm{P}$ quantificadas pelos extratores Mehlich-1, resina de troca iônica mista e Bray-1 correlacionaram-se mais com as frações $\mathrm{P}-\mathrm{H}_{2} \mathrm{O}$ e $\mathrm{P}$-Al, enquanto aquelas extraídas pelo Mehlich-3 correlacionaram-se mais com o P-Ca. Mehlich-1 e Bray-1 foram os extratores que mais se correlacionaram com a planta quanto à absorção de $\mathbf{P}$ nos solos estudados. Nos solos ricos em Ca e com pH elevado, o $\mathbf{P}$ extraído pelo Bray-1 foi baixo. Em geral, os teores de $\mathrm{P}$ pelo extrator Mehlich-1 foram semelhantes aos extraídos pela resina de troca iônica mista, mesmo nos solos ricos em Ca e com pH elevado.

Termos de indexação: fracionamento de fósforo, disponibilidade de fósforo, solos do semiárido.

\title{
SUMMARY: INORGANIC PHOSPHORUS FRACTIONS AND THEIR RELA- TIONSHIP WITH SOIL PHOSPHORUS EXTRACTED CHEMI- CALLY AND BY MAIZE PLANTS
}

\begin{abstract}
The fractionation of inorganic phosphorus (Pi) is important to evaluate in which forms phosphorus is sorbed to soil, because the efficiency of an extractant of available P in soils depends on its capacity to extract each fraction of soil Pi. This study evaluated the contents of Pi fractions in representative soils of the State of Paraiba and their relationship with the chemical and physical characteristics of these soils, as well as the correlation between the $P i$ fractions and P extracted from soils by maize plants and Mehlich-1, Mehlich-3, Bray-1, and by ion exchange resin extractors. The experiment was conducted in a greenhouse in a randomized block design and tested 12 soils, with and without $P$ application, in three replications. After the application of $P$ doses $\left(75,88\right.$ and $\left.103 \mathrm{mg} \mathrm{dm}^{-3}\right)$ in $3.0 \mathrm{dm}^{-3}$, soil samples were incubated in polyethylene pots for three weeks with distilled water (50\% of total porosity of each soil). Plant-available P was determined by four chemical extractants and the fractionation of Pi performed in sub samples of $0.2 \mathrm{dm}^{-3}$ per pot. The fractions $P$-Al and P-Fe were predominant in highly weathered soils and in less weathered soils with lower $\mathrm{pH}$ and $\mathrm{Ca}^{2+}$, while $\mathrm{P}$-Ca was preferentially found in alkaline soils with very high $\mathrm{Ca}^{2+}$ contents. Phosphorus extracted by maize plants as well as Mehlich-1, ion exchange resin and Bray-1 were found in $\mathrm{P}-\mathrm{H}_{2} \mathrm{O}$ and $\mathrm{P}$-Al fractions, while $\mathrm{P}$ extracted by Mehlich-3 was more correlated with P-Ca fraction. P extracted by Mehlich-1 and Bray-1 was more correlated with $P$ absorbed by plants, while P extracted by Bray-1 was low in soils with high $\mathrm{Ca}^{2+}$ contents and high $\mathrm{pH}$. In general, Mehlich-1 quantified P similar to ion exchange resin, even in $\mathrm{Ca}^{2+}$-rich soils with high $\mathrm{pH}$ values.
\end{abstract}

Index terms: P fractionation, phosphorus availability, semi-arid soils.

\section{INTRODUÇÃO}

O P do solo é distribuído em formas que variam com a natureza química do ligante e com a energia de ligação entre o nutriente e o solo. Quanto à natureza do ligante, o $\mathrm{P}$ pode ser encontrado como $\mathrm{P}$ orgânico diéster, $\mathrm{P}$ orgânico $(\mathrm{Po})$ monoéster e $\mathrm{P}$ inorgânico $(\mathrm{Pi})$ em ligações com $\mathrm{Fe}, \mathrm{Al}, \mathrm{Ca}$, argilas silicatadas e óxidos de $\mathrm{Fe}$ e de $\mathrm{Al}$. Assim, as formas de $\mathrm{P}$ do solo têm diferentes capacidades de dessorção e reposição da solução do solo, segundo sua natureza química e energia de ligação. O P orgânico tem maior importância em solos não cultivados e sob florestas, onde a matéria orgânica está mais preservada (Novais \& Smyth, 1999). Nos solos cultivados, o P inorgânico torna-se mais importante do que o orgânico, especialmente naqueles com baixos teores de matéria orgânica e que receberam adubações fosfatadas (Novais \& Smyth, 1999; Ranno et al., 2007).

Para melhor entendimento da dinâmica do P nos solos, é necessário conhecer as diferentes frações do elemento, mediante a utilização sequencial de diferentes soluções extratoras (Silva \& Raij, 1999). Entre os métodos de fracionamento, o mais conhecido é o de Chang \& Jackson (1957), que permite quantificar as diversas frações de $\mathrm{Pi}$ do solo, como o P ligado a $\mathrm{Al}$ (P-Al), o $\mathrm{P}$ ligado a $\mathrm{Fe}(\mathrm{P}-\mathrm{Fe})$ e o $\mathrm{P}$ ligado a $\mathrm{Ca}(\mathrm{P}-\mathrm{Ca})$, entre outras.

A eficiência dos extratores utilizados em laboratórios de rotina para avaliação da 
disponibilidade de P para as plantas está relacionada com a habilidade desses extratores em quantificar as diferentes frações de Pi dos solos que se relacionam positivamente com o $\mathrm{P}$ absorvido pelas plantas. Em estudos de fracionamento do Pi dos solos, tem sido observado que a planta absorve preferencialmente as formas de $\mathrm{P}$ ligadas a $\mathrm{Al}$ e a $\mathrm{Fe}$ e absorve pouco o P ligado a Ca (Novais \& Kamprath, 1978). O extrator Mehlich-1 superestima o P disponível em solos menos intemperizados e, ou, com $\mathrm{pH}$ mais elevado e em solos que receberam aplicação de fosfatos naturais pouco reativos, a qual eleva o $\mathrm{P}-\mathrm{Ca}$ nesses solos (Silva \& Raij, 1999). Por outro lado, extratores que não extraem ou não têm preferência em extrair P-Ca, como a resina de troca aniônica, o Bray-1 e o Mehlich-3, deverão ser mais adequados que o Mehlich-1 para esses solos (Bahia Filho et al., 1983; Novelino et al., 1985; Moreira \& Malavolta, 2001), que é o caso da maioria dos solos do Estado da Paraíba.

Segundo Silveira et al. (2006), na região Nordeste do Brasil são poucos os estudos que tratam do comportamento do P no solo. No Estado da Paraíba, apenas nos trabalhos de Farias et al. $(2009 a, b)$ foram estudadas a adsorção de $\mathrm{P}$ aos solos e a disponibilidade de $\mathrm{P}$ para as plantas, a qual foi avaliada pelos extratores Mehlich-1, Mehlich-3, Bray-1 e resina de troca iônica mista. Contudo, nesses trabalhos não foi realizado o fracionamento do Pi do solo para saber a correlação entre os teores das frações de Pi do solo e os teores de P extraídos do solo pela planta e por esses extratores.

Considerando que os laboratórios de rotina de fertilidade do solo do Estado da Paraíba só utilizam o Mehlich-1 para quantificar o P disponível e que grande parte do Estado possui solos pouco intemperizados e que têm alta probabilidade de formação de P-Ca, faz-se necessário conhecer as formas inorgânicas de $\mathrm{P}$ e avaliar a eficiência do Mehlich-1 e de outros extratores na quantificação do P disponível do solo para as plantas. Diante do exposto, objetivou-se avaliar os teores das frações de Pi em solos representativos do Estado da Paraíba e correlacioná-los com características químicas e físicas e com o $\mathrm{P}$ extraído dos solos pelos extratores Mehlich-1, Mehlich-3, Bray-1 e resina de troca iônica mista e pelo milho.

\section{MATERIAL E MÉTODOS}

O experimento foi realizado em casa de vegetação, no Departamento de Solos e Engenharia Rural do Centro de Ciências Agrárias da Universidade Federal da Paraíba. Foram utilizadas amostras de 12 solos que compõem o banco de solos representativos do Estado da Paraíba (Oliveira et al., 2006). Os solos utilizados foram classificados como (Embrapa, 2006): Neossolo Regolítico (RR), Neossolo Litólico (RL), Argissolo Acinzentado (PAC), Neossolo Flúvico (RY), Argissolo Amarelo (PA), Latossolo Amarelo (LA), Luvissolo Háplico (TX), Planossolo Háplico (SX), Argissolo Vermelho-Amarelo (PVA), Argissolo Vermelho eutrófico (PVe), Argissolo Vermelho distrófico (PVd) e Vertissolo Háplico (VX). As amostras foram coletadas na profundidade de 0-30 cm, secas ao ar e passadas em peneira de $4 \mathrm{~mm}$, para o experimento em vasos, e em peneira de $2 \mathrm{~mm}$, para as análises químicas e físicas (Quadro 1). A necessidade de calagem dos solos foi calculada pelos métodos da neutralização do $\mathrm{Al}^{3+}$ e elevação dos teores de $\mathrm{Ca}^{2+}+\mathrm{Mg}^{2+}$ e pelo método da saturação por bases (Ribeiro et al., 1999). A quantidade de calcário foi calculada considerando-se a média aritmética dos valores de necessidade de calagem estimados por esses dois métodos. Apenas os solos PA, PAC, PVA e PVd receberam calagem, aplicandose uma mistura de $\mathrm{CaCO}_{3}$ (p.a.) e de $\mathrm{MgCO}_{3}$ (p.a.) numa relação molar 4:1. Posteriormente, eles foram incubados por duas semanas, com uma quantidade de água correspondente a $50 \%$ da porosidade total de cada solo.

Após esse período, as amostras de solos receberam a dose de $\mathrm{P}$, calculada de acordo com o $\mathrm{P}$ remanescente (Alvarez V. et al., 2000). Ela foi homogeneizada em $100 \%$ do volume de solo de cada vaso $\left(3 \mathrm{dm}^{3}\right)$, antes de ser realizado o fracionamento do Pi. O P foi aplicado na dose de $75 \mathrm{mg} \mathrm{dm} \mathrm{dm}^{-3}$ nos solos PAC e RR, de $88 \mathrm{mg} \mathrm{dm}^{-3}$ nos solos PA, PVe, LA, RL, TX, SX e RY e de $103 \mathrm{mg} \mathrm{dm}^{-3}$ nos solos PVA, PVd e VX. Em todos os solos, utilizou-se uma testemunha, em que não foi aplicado $\mathrm{P}$. Como fonte de $\mathrm{P}$, foi utilizado o $\mathrm{KH}_{2} \mathrm{PO}_{4}$ (p.a.), via solução. Após a aplicação da dose de $\mathrm{P}$ ao solo de cada vaso, seguiu-se um período de incubação por três semanas, adicionando-se água destilada em quantidade correspondente a $50 \%$ da porosidade total de cada solo.

Após esse período de incubação, os solos foram retirados dos vasos, secos ao ar, destorroados, passados em peneira de $4 \mathrm{~mm}$ de malha e devolvidos aos vasos. Subamostras de $0,2 \mathrm{dm}^{3}$ do solo de cada vaso foram coletadas e passadas em peneira de $2 \mathrm{~mm}$ de malha, para determinação dos teores de $\mathrm{P}$ disponíveis pelos extratores Mehlich-1 (Mehlich, 1953), Mehlich-3 (Mehlich, 1984), Bray-1 (Bray \& Kurtz, 1945) e resina de troca iônica mista saturada com bicarbonato de sódio (Raij et al., 2001). Os extratores Mehlich-1, Mehlich-3 e Bray-1 foram utilizados na relação solo:solução (v/v) de 1:10 e tempo de agitação de $5 \mathrm{~min}$. Nessas mesmas amostras, foi realizado o fracionamento sequencial do Pi proposto originalmente por Chang \& Jackson (1957), mas seguindo o método descrito em Kuo (1996), com algumas modificações, conforme sequência de procedimentos descrita a seguir. 
Quadro 1. Características químicas e físicas e procedência das amostras dos solos ${ }^{(1)}$

\begin{tabular}{|c|c|c|c|c|c|c|c|c|c|c|c|c|}
\hline \multirow{2}{*}{ Característica } & \multicolumn{12}{|c|}{ Solo $^{(2)}$} \\
\hline & $\mathbf{R R}$ & RL & PAC & $\mathbf{R Y}$ & PA & LA & TX & $\mathbf{S X}$ & PVA 1 & PVe & PVd & VX \\
\hline $\mathrm{pH}\left(\mathrm{H}_{2} \mathrm{O}\right)$ & 7,0 & 6,2 & 4,4 & 7,3 & 5,9 & 5,9 & 6,2 & 7,2 & 5,5 & 6,3 & 5,0 & 8,4 \\
\hline $\mathrm{CO}\left(\mathrm{g} \mathrm{kg}^{-1}\right)$ & 3,4 & 3,8 & 10,7 & 8,9 & 3,5 & 5,9 & 7,6 & 4,3 & 10,7 & 9,0 & 8,0 & 3,7 \\
\hline P-rem $\left(\mathrm{mg} \mathrm{L}^{-1}\right)^{(3)}$ & 54 & 45 & 47 & 44 & 45 & 44 & 41 & 37 & 28 & 35 & 28 & 25 \\
\hline CMAP $\left(\mathrm{mg} \mathrm{g}^{-1}\right)^{(4)}$ & 0,036 & 0,130 & 0,144 & 0,172 & 0,174 & 0,176 & 0,177 & 0,248 & 0,288 & 0,297 & 0,347 & 0,435 \\
\hline $\mathrm{P}\left(\mathrm{mg} \mathrm{dm}^{-3}\right)^{(8)}$ & 24,07 & 4,31 & 3,59 & 144,33 & 1,52 & 11,42 & 4,35 & 21,58 & 2,63 & 6,80 & 2,32 & 19,77 \\
\hline $\mathrm{K}^{+}\left(\mathrm{cmol}_{\mathrm{c}} \mathrm{dm}^{-3}\right)$ & 1,8 & 1,9 & 1,0 & 6,0 & 0,4 & 1,8 & 6,4 & 2,1 & 2,4 & 3,9 & 1,9 & 6,9 \\
\hline $\mathrm{Ca}^{2+}\left(\mathrm{cmol}_{\mathrm{c}} \mathrm{dm}^{-3}\right)$ & 18,0 & 20,0 & 8,0 & 110,0 & 6,0 & 16,0 & 61,0 & 122,0 & 11,0 & 54,0 & 19,0 & 291,0 \\
\hline $\mathrm{Mg}^{2+}\left(\mathrm{cmol}_{\mathrm{c}} \mathrm{dm}^{-3}\right)$ & 9,0 & 11,0 & 6,0 & 40,0 & 4,0 & 11,5 & 40,0 & 56,0 & 13,0 & 18,0 & 8,0 & 104,0 \\
\hline$(\mathrm{H}+\mathrm{Al})\left(\mathrm{cmol}_{\mathrm{c}} \mathrm{dm}^{-3}\right)$ & 10,7 & 22,9 & 56,7 & 12,2 & 16,8 & 21,4 & 29,0 & 15,3 & 55,0 & 27,5 & 42,8 & 7,6 \\
\hline CTC $\left(\mathrm{cmol}_{\mathrm{c}} \mathrm{dm}^{-3}\right)$ & 29,0 & 35,9 & 24,9 & 156,9 & 11,7 & 30,4 & 108,9 & 183,1 & 30,0 & 76,3 & 32,4 & 423,7 \\
\hline V (\%) & 73 & 61 & 21 & 93 & 39 & 59 & 79 & 92 & 33 & 74 & 41 & 98 \\
\hline Areia $\left(\mathrm{g} \mathrm{kg}^{-1}\right)$ & 890 & 810 & 840 & 450 & 880 & 650 & 670 & 640 & 660 & 580 & 490 & 220 \\
\hline Silte $\left(\mathrm{g} \mathrm{kg}^{-1}\right)$ & 80 & 110 & 40 & 350 & 30 & 60 & 190 & 170 & 110 & 240 & 130 & 350 \\
\hline Argila $\left(\mathrm{g} \mathrm{kg}^{-1}\right)$ & 30 & 80 & 120 & 200 & 90 & 290 & 140 & 190 & 230 & 180 & 380 & 430 \\
\hline $\mathrm{Fe}_{\mathrm{d}}\left(\mathrm{g} \mathrm{kg}^{-1}\right)^{(5)}$ & 0,71 & 2,13 & 2,02 & 5,05 & 3,84 & 7,63 & 4,69 & 11,5 & 9,54 & $4 \quad 12,94$ & 7,63 & 6,74 \\
\hline $\mathrm{Fe}_{\circ}\left(\mathrm{g} \mathrm{kg}^{-1}\right)^{(6)}$ & 0,17 & 0,66 & 0,18 & 1,09 & 0,13 & 0,25 & 0,79 & 0,66 & 0,84 & 2,73 & 0,25 & 0,97 \\
\hline $\mathrm{Al}_{\mathrm{d}}\left(\mathrm{g} \mathrm{kg}^{-1}\right)^{(5)}$ & 0,04 & 0,21 & 1,08 & 0,29 & 0,94 & 1,12 & 0,38 & 0,42 & 1,61 & 1,47 & 1,12 & 0,54 \\
\hline $\mathrm{Al}_{\mathrm{o}}\left(\mathrm{g} \mathrm{kg}^{-1}\right)^{(6)}$ & 0,04 & 0,16 & 0,27 & 0,27 & 0,27 & 0,33 & 0,33 & 0,33 & 0,62 & $2 \quad 0,68$ & 0,33 & 1,03 \\
\hline Minerais $^{(7)}$ & $\begin{array}{l}\mathrm{Ct}, \mathrm{Mi}, \\
\mathrm{Qz}, \\
(2: 1)\end{array}$ & $\begin{array}{l}\mathrm{Mi}, \\
\mathrm{Ct} \\
(2: 1)\end{array}$ & $\mathrm{Ct}, \mathrm{Gt}$ & $\begin{array}{l}\mathrm{Mi}, \\
\mathrm{Ct}, \\
(2: 1)\end{array}$ & $\begin{array}{l}\mathrm{Ct}, \\
\mathrm{Gb}, \\
\mathrm{Gt}\end{array}$ & $\begin{array}{l}\mathrm{Ct}, \\
\mathrm{Gb}, \\
\mathrm{Gt}\end{array}$ & $\begin{array}{l}\mathrm{Ct}, \mathrm{Mi} \\
(2: 1), \mathrm{Fp}\end{array}$ & $\begin{array}{l}(2: 1), \\
\mathrm{Mi}, \\
\mathrm{Ct}, \mathrm{Gt}\end{array}$ & $\begin{array}{l}\mathrm{Ct}, \\
\mathrm{Gt}\end{array}$ & $\begin{array}{l}\mathrm{Ct}, \mathrm{Gt}, \\
\mathrm{Mi}, \\
(2: 1)\end{array}$ & $\begin{array}{l}\mathrm{Ct}, \mathrm{Gt} \\
\mathrm{Mi}, \\
\mathrm{Hm}\end{array}$ & $\begin{array}{l}(2: 1) \\
\mathrm{Qz} \\
\mathrm{Mi}\end{array}$ \\
\hline $\begin{array}{l}\text { Município } \\
\text { de coleta }\end{array}$ & $\begin{array}{l}\text { Espe- } \\
\text { rança }\end{array}$ & $\begin{array}{l}\text { Sole- } \\
\text { dade }\end{array}$ & $\begin{array}{l}\text { Maman- } \\
\text { guape }\end{array}$ & Souza & Conde & Cuité & $\begin{array}{l}\text { São Miguel } \\
\text { de Taipu }\end{array}$ & Cuité & Areia & $\begin{array}{l}\text { Marizó - } \\
\text { polis }\end{array}$ & $\begin{array}{l}\text { Alagoa } \\
\text { Grande }\end{array}$ & Souza \\
\hline
\end{tabular}

(1)Segundo métodos descritos em Embrapa (1997). Dados apresentados originalmente em Farias et al. (2009a). ${ }^{(2)}$ De acordo com o Sistema Brasileiro de Classificação de Solos (Embrapa, 2006): RR: Neossolo Regolítico, RL: Neossolo Litólico, PAC: Argissolo Acinzentado, RY: Neossolo Flúvico, PA: Argissolo Amarelo, LA: Latossolo Amarelo, TX: Luvissolo Háplico, SX: Planossolo Háplico, PVA: Argissolo Vermelho-Amarelo, PVe: Argissolo Vermelho eutrófico, PVd: Argissolo Vermelho distrófico, VX: Vertissolo Háplico. ${ }^{(3)}$ Fósforo remanescente (Alvarez V. et al., 2000). ${ }^{(4)}$ Capacidade máxima de adsorção de fosfato. ${ }^{(5)}$ Óxidos de Fe e de Al, extraídos com ditionito-citrato-bicarbonato. ${ }^{(6)}$ Óxidos de $\mathrm{Fe}$ e de Al extraídos com oxalato de amônio. ${ }^{(7)}$ Minerais predominantes na fração argila. Ct: caulinita; Gb: gibbsita; Gt: goethita; Mi: mica; (2:1): argilomineral tipo 2:1; Hm: hematita; Qz: quartzo; Fp: feldspatos. (8)Fósforo disponível extraído por Mehlich-1.

\section{Extração do Pi facilmente solúvel $\left(\mathrm{P}-\mathrm{H}_{2} \mathrm{O}\right)$}

Foi colocado 0,5 g de solo (TFSA) em erlenmeyer de $125 \mathrm{~mL}$ contendo $25 \mathrm{~mL}$ de $\mathrm{NH}_{4} \mathrm{Cl} 1 \mathrm{~mol} \mathrm{~L}^{-1}$, seguido de agitação durante 30 min em agitador horizontal. Passado esse período, a suspensão foi centrifugada durante 5 min a $1.800 \mathrm{rpm}$, sendo o sobrenadante filtrado em papel de filtração lenta e transferido para balão volumétrico de $50 \mathrm{~mL}$, que teve seu volume completado com água deionizada (extrato A), no qual determinou-se a concentração de $\mathrm{P}$ e calculou-se o teor de $\mathrm{P}-\mathrm{H}_{2} \mathrm{O}$ no solo.

\section{Extração do Pi ligado ao alumínio (P-Al)}

O resíduo de solo do tubo de centrífuga foi transferido para erlenmeyer de $125 \mathrm{~mL}$, no qual foram adicionados $25 \mathrm{~mL}$ de $\mathrm{NH}_{4} \mathrm{~F} 0,5 \mathrm{~mol} \mathrm{~L}^{-1}$ (pH 8,2), seguido de agitação em agitador horizontal por uma hora. Após esse período, a suspensão foi centrifugada durante $5 \mathrm{~min}$ a $1.800 \mathrm{rpm}$, e o sobrenadante, filtrado em papel-filtro e transferido para balão volumétrico de $50 \mathrm{~mL}$ (extrato B). O resíduo de solo foi lavado duas vezes com porções de $12,5 \mathrm{~mL}$ de $\mathrm{NaCl}$ saturado e depois centrifugado. Essas soluções de lavagem foram misturadas com o extrato B, e o volume, ajustado para $50 \mathrm{~mL}$ com água deionizada, no qual foi determinada a concentração de $\mathrm{P}$ e calculado o teor de $\mathrm{P}-\mathrm{Al}$ no solo.

\section{Extração do Pi ligado a ferro (P-Fe)}

O resíduo de solo do tubo de centrífuga foi transferido para erlenmeyer de $125 \mathrm{~mL}$, seguido da adição de $25 \mathrm{~mL}$ de $\mathrm{NaOH} 0,1 \mathrm{~mol} \mathrm{~L}^{-1}$ e agitação por $17 \mathrm{~h}$. Após esse período, a suspensão foi centrifugada durante $5 \mathrm{~min}$ a $1.800 \mathrm{rpm}$, e o sobrenadante, filtrado em papel de filtro e transferido para balão volumétrico de $50 \mathrm{~mL}$ (extrato $\mathrm{C}$ ). O resíduo de solo foi lavado duas vezes com porções de $12,5 \mathrm{~mL}$ 
de $\mathrm{NaCl}$ saturado e, a seguir, centrifugado. Essas soluções de lavagem foram misturadas com o extrato $\mathrm{C}$, e o volume foi ajustado para $50 \mathrm{~mL}$ com água deionizada. Para eliminar a turbidez do extrato $\mathrm{C}$, adicionaram-se $4 \mathrm{~mL}$ de $\mathrm{H}_{2} \mathrm{SO}_{4}$ $1 \mathrm{~mol} \mathrm{~L}^{-1}$, seguido de agitação deste com bastão de vidro. Quando necessário, adicionaram-se gotas de $\mathrm{H}_{2} \mathrm{SO}_{4}$ concentrado até a floculação completa dos coloides. Na sequência, o extrato $\mathrm{C}$ foi centrifugado novamente durante 5 min a $1.800 \mathrm{rpm}$ e filtrado em papel-filtro para obtenção de um extrato límpido, a ser transferido para balão volumétrico de $50 \mathrm{~mL}$. Em seguida, determinou-se a concentração de $\mathrm{P}$ no extrato $\mathrm{C}$ e calculou-se o teor de P-Fe no solo.

\section{Extração do Pi ligado a cálcio (P-Ca)}

O resíduo de solo remanescente da extração do $\mathrm{P}$-Fe foi transferido para erlenmeyer de $125 \mathrm{~mL}$, no qual foram adicionados $25 \mathrm{~mL}$ de $\mathrm{H}_{2} \mathrm{SO}_{4} 0,25 \mathrm{~mol} \mathrm{~L}^{-1}$; a seguir, a suspensão foi agitada durante uma hora. Após esse período, a suspensão foi centrifugada durante 10 min a $1.800 \mathrm{rpm}$ e filtrada em papel-filtro, e o sobrenadante, transferido para balão volumétrico de $50 \mathrm{~mL}$ (extrato D). O resíduo de solo foi lavado duas vezes com porções de $12,5 \mathrm{~mL}$ de $\mathrm{NaCl}$ saturado e, em seguida, a suspensão foi centrifugada. Essas soluções de lavagem foram misturadas com o extrato $\mathrm{D}$, e o volume, ajustado para $50 \mathrm{~mL}$ com água deionizada. Na sequência, foi determinada a concentração de $\mathrm{P}$ no extrato $\mathrm{D}$ e calculado o teor de P-Ca no solo.

A dosagem de $\mathrm{P}$ nos extratos foi feita por colorimetria, conforme Braga \& Defelipo (1974). O Pi total (Pi-total) foi obtido mediante a soma dos teores de $\mathrm{P}-\mathrm{H}_{2} \mathrm{O}$, P-Al, P-Fe e P-Ca. Os teores das frações de $\mathrm{Pi}$ em cada um dos 12 solos foram determinados em três repetições, e a média foi calculada.

$\mathrm{O}$ experimento em casa de vegetação foi realizado em esquema fatorial $12 \times 2$, no delineamento de blocos casualizados, com 24 tratamentos (12 solos x 2 doses de P) e três repetições. Cada unidade experimental foi constituída de um vaso plástico, sem dreno, contendo $2,8 \mathrm{dm}^{3}$ de solo, e duas plantas de milho. Antes do plantio, foram aplicados $50 \mathrm{mg} \mathrm{dm}^{-3}$ de $\mathrm{N}\left(\left(\mathrm{NH}_{4}\right)_{2} \mathrm{SO}_{4}\right), 80 \mathrm{mg} \mathrm{dm}-3$ de $\mathrm{S}\left(\left(\mathrm{NH}_{4}\right)_{2} \mathrm{SO}_{4}\right)$, $0,5 \mathrm{mg} \mathrm{dm}^{-3}$ de $\mathrm{B}\left(\mathrm{H}_{3} \mathrm{BO}_{3}\right), 1,5 \mathrm{mg} \mathrm{dm}^{-3} \mathrm{de} \mathrm{Cu}^{-3}$ $\left(\mathrm{CuSO}_{4} \cdot 5 \mathrm{H}_{2} \mathrm{O}\right), 4 \mathrm{mg} \mathrm{dm}{ }^{-3}$ de $\mathrm{Mn}\left(\mathrm{MnCl}_{2} \cdot 4 \mathrm{H}_{2} \mathrm{O}\right)$, $4 \mathrm{mg} \mathrm{dm}{ }^{-3}$ de $\mathrm{Zn}\left(\mathrm{ZnSO}_{4} \cdot 7 \mathrm{H}_{2} \mathrm{O}\right), 5 \mathrm{mg} \mathrm{dm}^{-3}$ de $\mathrm{Fe}$ $\left(\mathrm{FeCl}_{3} \cdot 6 \mathrm{H}_{2} \mathrm{O}\right.$, dissolvido em solução diluída de EDTA) e $0,15 \mathrm{mg} \mathrm{dm}^{-3}$ de $\mathrm{Mo}\left(\left(\mathrm{NH}_{4}\right)_{6} \mathrm{Mo}_{7} \mathrm{O}_{24} \cdot 4 \mathrm{H}_{2} \mathrm{O}\right)$. Parte da dose do $\mathrm{S}$ foi aplicada junto ao $\mathrm{N}$ na adubação de plantio, e o restante, na primeira adubação nitrogenada de cobertura. Nas outras três adubações nitrogenadas de cobertura a ureia foi utilizada como fonte de N (Farias et al., 2009b).

Trinta e cinco dias após a semeadura, foi efetuado o corte da parte aérea das plantas de cada vaso, a $1 \mathrm{~cm}$ do solo. Em seguida, o material vegetal foi lavado em água corrente de torneira e, posteriormente, com água destilada, submetido a uma pré-secagem ainda na casa de vegetação e acondicionado em saco de papel perfurado. Para completar a secagem, o material foi levado a uma estufa de circulação forçada de ar, a $70^{\circ} \mathrm{C}$, até peso constante, e depois pesado para obtenção da massa da matéria seca. Depois de pesada, a matéria seca da parte aérea foi triturada em moinho tipo Willey e mineralizada por digestão sulfúrica (Tedesco et al., 1995), seguida da determinação do $P$ nos extratos, por colorimetria (Braga \& Defelipo, 1974).

A análise estatística consistiu das análises de correlação entre os teores das frações de Pi e os valores de algumas características químicas e físicas dos solos e entre os teores de P do solo extraídos pelos extratores e o conteúdo de $\mathrm{P}$ acumulado na parte aérea da planta.

\section{RESULTADOS E DISCUSSÃO}

Os solos diferiram quanto aos teores de $\mathrm{P}$ inorgânico total (Pi-total), os quais variaram de 33,4 a $233,6 \mathrm{mg} \mathrm{dm}^{-3}$ na ausência de adubação fosfatada e de 75,1 a $297,9 \mathrm{mg} \mathrm{dm}^{-3}$ nesses mesmos solos após a aplicação do P (Quadro 2). Os maiores teores de Pi-total foram observados nos solos menos intemperizados, especialmente naqueles com maior teor de argila (SX, RY e VX). Essas diferenças entre solos em relação aos teores de Pi-total devem-se, provavelmente, aos diferentes teores de $\mathrm{P}$ nos materiais de origem, ao histórico de adubações fosfatadas antes da coleta no campo e ao menor grau de desenvolvimento pedogenético dos solos formados sob clima semiárido (Silveira et al., 2006; Ranno et al., 2007).

Os teores de $\mathrm{Pi}$ solúvel $\left(\mathrm{Pi}-\mathrm{H}_{2} \mathrm{O}\right)$ foram baixos $\left(<2,0 \mathrm{mg} \mathrm{dm}^{-3}\right)$ em todos os solos e não aumentaram após a aplicação das doses de $\mathrm{P}$, com exceção dos solos RY e RR, cujos valores de Pi solúvel passaram de 3,23 e $9,32 \mathrm{mg} \mathrm{dm}^{-3}$ para 24,98 e $24,07 \mathrm{mg} \mathrm{dm}^{-3}$, respectivamente (Quadro 2). A aplicação de $75 \mathrm{mg} \mathrm{dm}^{-3}$ de $\mathrm{P}$ no solo RR, que é o de menor teor de argila e menor capacidade máxima de adsorção de fosfato (CMAP) (Quadro 1), aumentou em aproximadamente oito vezes o teor de $\mathrm{Pi}-\mathrm{H}_{2} \mathrm{O}$, o qual passou a representar $26 \%$ do Pi-total (Quadro 2). Em outros trabalhos (Ranno et al., 2007; Souza et al., 2007) também foi verificado que os teores de $\mathrm{Pi}-\mathrm{H}_{2} \mathrm{O}$ nos solos são baixos, o que revela a forte interação do $\mathrm{P}$ com a fase sólida do solo.

Nos solos mais intemperizados, e naqueles menos intemperizados com valores baixos de $\mathrm{pH}$ e de $\mathrm{Ca}^{2+}$, a maior parte do Pi ocorreu nas formas de $\mathrm{P}-\mathrm{Al}$ e de $\mathrm{P}-\mathrm{Fe}$ (em média, 45 e $37 \%$ do total), ao 
Quadro 2. Teores das frações de P inorgânico em solos do Estado da Paraíba, em função de doses de P aplicadas

\begin{tabular}{|c|c|c|c|c|c|c|}
\hline \multirow{2}{*}{ Solo } & \multirow{2}{*}{ Dose de $P$} & \multicolumn{5}{|c|}{ Fração de $P$ inorgânico } \\
\hline & & Pi-Total ${ }^{(1)}$ & $\mathrm{P}-\mathrm{H}_{2} \mathrm{O}$ & P-Al & P-Fe & P-Ca \\
\hline & & & Solos ma & mperizado & & \\
\hline \multirow[t]{2}{*}{$\mathrm{PA}$} & 0 & 34,6 & $1,2(04)^{(3)}$ & $15,3(44)$ & $14,0(40)$ & $4,2(12)$ \\
\hline & 88 & 81,8 & $3,1(04)$ & $52,0(63)$ & $21,4(26)$ & $5,3(07)$ \\
\hline \multirow[t]{2}{*}{ PAC } & 0 & 33,4 & $1,4(04)$ & $21,7(65)$ & $6,6(20)$ & $3,7(11)$ \\
\hline & 75 & 75,1 & $5,0(07)$ & $52,6(69)$ & $13,2(18)$ & $4,2(06)$ \\
\hline \multirow[t]{2}{*}{ PVe } & 0 & 73,9 & $1,9(03)$ & $22,0(30)$ & $33,9(45)$ & $16,0(22)$ \\
\hline & 88 & 129,6 & $4,2(03)$ & $55,5(43)$ & $51,0(39)$ & $18,8(15)$ \\
\hline \multirow[t]{2}{*}{ PVA } & 0 & 41,0 & $1,4(03)$ & $12,4(30)$ & $19,9(49)$ & 7,3 (18) \\
\hline & 103 & 107,6 & $2,4(02)$ & $50,3(47)$ & $43,8(41)$ & $11,1(10)$ \\
\hline \multirow[t]{2}{*}{ LA } & 0 & 70,5 & $1,5(02)$ & $21,7(31)$ & $35,8(51)$ & $11,5(16)$ \\
\hline & 88 & 115,6 & $5,2(04)$ & $48,1(42)$ & $49,9(43)$ & $12,4(11)$ \\
\hline \multirow[t]{3}{*}{ PVd } & 0 & 44,8 & $1,2(03)$ & $15,1(34)$ & $21,6(48)$ & $6,8(15)$ \\
\hline & 103 & 98,3 & $2,9(03)$ & $38,8(39)$ & $46,8(48)$ & $9,9(10)$ \\
\hline & \multicolumn{6}{|c|}{ Solos menos intemperizados ${ }^{(4)}$} \\
\hline \multirow[t]{2}{*}{$\mathrm{RR}$} & 0 & 51,0 & $3,2(06)$ & $24,2(48)$ & $15,4(30)$ & $8,1(16)$ \\
\hline & 75 & 96,5 & $24,9(26)$ & $43,3(45)$ & $19,5(20)$ & $8,9(09)$ \\
\hline \multirow[t]{2}{*}{ RL } & 0 & 39,8 & $1,9(05)$ & $17,4(44)$ & $13,9(35)$ & $6,5(16)$ \\
\hline & 88 & 84,3 & $5,2(06)$ & $46,1(55)$ & $24,1(29)$ & $8,8(10)$ \\
\hline \multirow[t]{2}{*}{$\mathrm{TX}$} & 0 & 44,9 & $1,7(04)$ & $13,3(30)$ & $21,5(48)$ & $8,5(19)$ \\
\hline & 88 & 111,9 & $5,1(05)$ & $54,2(48)$ & $38,1(34)$ & 14,5 (13) \\
\hline \multirow[t]{2}{*}{ SX } & 0 & 157,2 & $1,8(01)$ & $21,4(14)$ & $22,4(14)$ & $111,6(71)$ \\
\hline & 88 & 204,8 & $5,1(02)$ & $44,5(22)$ & $36,7(18)$ & $118,2(58)$ \\
\hline \multirow[t]{2}{*}{ RY } & 0 & 233,6 & $9,3(04)$ & $52,4(22)$ & $42,2(18)$ & $129,7(56)$ \\
\hline & 88 & 297,9 & $24,1(09)$ & $82,9(24)$ & $58,7(21)$ & $132,3(46)$ \\
\hline \multirow{2}{*}{ VX } & 0 & 82,3 & $2,6(03)$ & 15,4 (19) & $12,0(14)$ & $52,3(64)$ \\
\hline & 103 & 182,2 & $5,9(03)$ & $75,9(42)$ & $40,7(22)$ & $59,6(33)$ \\
\hline
\end{tabular}

(1) Pi-total $=$ P-H $\mathrm{H}_{2} \mathrm{O}+\mathrm{P}$-Al $+\mathrm{P}-\mathrm{Fe}+\mathrm{P}$-Ca. ${ }^{(2)}$ Valores de Ki $\leq 2,46$ (Oliveira et al., 2006) (3) Valores em parênteses são expressos em percentagem e referem-se à contribuição de cada fração de Pi para o Pi-total. (4) Valores de Ki $\geq 2,46$ (Oliveira et al., 2006).

passo que nos solos com $\mathrm{pH}$ alcalino e teores muito elevados de $\mathrm{Ca}^{2+}$ (SX, RY e VX) o Pi foi encontrado principalmente na forma de P-Ca (Quadro 2). Isso também pode ser confirmado pela análise de correlação (Quadro 3), pois os teores de P-Ca correlacionaram-se positivamente com os teores de $\mathrm{Ca}^{2+}\left(\mathrm{r}=0,58^{* *}\right)$ e com os valores de $\mathrm{pH}\left(\mathrm{r}=0,62^{* *}\right)$ e de saturação por bases $\left(r=0,69^{* *}\right)$.

Nos solos ácidos e pobres em $\mathrm{Ca}^{2+}$, a maior parte do $\mathrm{P}$ nativo, bem como do $\mathrm{P}$ adicionado como fertilizante, forma precipitados com $\mathrm{Al}$ e $\mathrm{Fe}$ e, ou, é adsorvida especificamente à superfície dos coloides minerais, de modo que as frações $\mathrm{P}-\mathrm{Al}$ e $\mathrm{P}$-Fe são as que predominam. A predominância dessas frações de P também foi observada por Silva et al. (2003), que, trabalhando com três Latossolos, verificaram que, em média, mais de $80 \%$ do $\mathrm{P}$ inorgânico apresenta-se nas frações P-Al e P-Fe. Por outro lado, nos solos alcalinos e com teores elevados de $\mathrm{Ca}^{2+}$, tanto o $\mathrm{P}$ nativo como o $\mathrm{P}$ adicionado como fertilizante precipitam com o $\mathrm{Ca}^{2+}$ da solução do solo, formando fosfatos de Ca pouco solúveis (Gatiboni et al., 2007). Nos solos menos intemperizados, que apresentam pH neutro ou alcalino e têm teores elevados de $\mathrm{Ca}^{2+}$, o P-Ca foi a fração de Pi predominante, representando, em média, $55 \%$ do Pi-total.

A aplicação de $\mathrm{P}$ aos solos aumentou os teores de todas as frações de Pi dos solos, sobretudo do P-Al e P-Fe (Quadro 2). Atenção deve ser dada ao ocorrido nos solos SX, RY e VX, onde se esperava aumento dos teores de $\mathrm{P}-\mathrm{Ca}$, pelo fato de eles serem alcalinos e muito ricos em $\mathrm{Ca}^{2+}$ (Quadro 1). Nesses solos, a fração P-Al foi a que mais aumentou (Quadro 2), porém não é possível garantir que todo esse P-Al seja de fato $\mathrm{P}$ ligado a $\mathrm{Al}$. Na extração sequencial das frações de $\mathrm{Pi}$, o $\mathrm{P}$-Al é extraído com $\mathrm{NH}_{4} \mathrm{~F}$ antes da extração do P-Ca, e em solos alcalinos e ricos em $\mathrm{Ca}^{2+}$ o íon fluoreto pode complexar Ca ligado a $\mathrm{P}$ para formar $\mathrm{CaF}_{2}$ (Kuo, 1996). Outro fato a considerar é que, na presença de adubação fosfatada, verificouse correlação positiva (Quadro 3) entre o P-Al e os teores de $\mathrm{Ca}^{2+}\left(\mathrm{r}=0,67^{* *}\right)$ e os valores de $\mathrm{pH}(\mathrm{r}=$ $\left.0,57^{* *}\right)$ e de saturação por bases $\left(r=0,51^{*}\right)$. Portanto, é provável que parte do P-Al extraído dos solos SX, RY e VX seja P-Ca. 
Quadro 3. Coeficientes de correlação linear simples entre os teores das frações de P inorgânico do solo e os valores de características químicas e físicas dos solos

\begin{tabular}{|c|c|c|c|c|c|c|}
\hline Fração & $\mathrm{pH}$ & $\mathbf{C a}$ & $\mathrm{V}$ & Prem & Argila & Fed \\
\hline \multicolumn{7}{|c|}{ Todas as doses juntas $(\mathrm{n}=24)$} \\
\hline Pi-total & $0,55^{*}$ & $0,49^{*}$ & $0,63^{*}$ & $-0,08^{\mathrm{ns}}$ & $0,20^{\text {ns }}$ & $-0,05^{\mathrm{ns}}$ \\
\hline $\mathrm{P}-\mathrm{H}_{2} \mathrm{O}$ & $0,35^{*}$ & $0,10^{\text {ns }}$ & $0,35^{*}$ & $0,37^{*}$ & $-0,20^{\mathrm{ns}}$ & $-0,30^{\mathrm{ns}}$ \\
\hline $\mathrm{P}-\mathrm{Al}$ & $0,26^{\mathrm{ns}}$ & $0,24^{\mathrm{ns}}$ & $0,26^{\mathrm{ns}}$ & $0,04^{\mathrm{ns}}$ & $0,06^{\mathrm{ns}}$ & $-0,17^{\mathrm{ns}}$ \\
\hline $\mathrm{P}-\mathrm{Fe}$ & $0,20^{\mathrm{ns}}$ & $0,14^{\mathrm{ns}}$ & $0,34^{\mathrm{ns}}$ & $-0,26^{\mathrm{ns}}$ & $0,37^{*}$ & $0,35^{*}$ \\
\hline $\mathrm{P}-\mathrm{Ca}$ & $0,62^{*}$ & $0,58^{*}$ & $0,69^{*}$ & $-0,11^{\mathrm{ns}}$ & $0,20^{\text {ns }}$ & $-0,06^{\mathrm{ns}}$ \\
\hline Planta $^{(1)}$ & $0,29^{\mathrm{ns}}$ & $0,08^{\mathrm{ns}}$ & $0,35^{*}$ & $0,36^{*}$ & $-0,18^{\mathrm{ns}}$ & $-0,27^{\mathrm{ns}}$ \\
\hline \multicolumn{7}{|c|}{ Dose de $\mathrm{P}=0 \mathrm{mg} \mathrm{dm}^{-3}(\mathrm{n}=12)$} \\
\hline Pi-total & $0,56^{*}$ & $0,44^{\mathrm{ns}}$ & $0,66^{*}$ & $0,00^{\mathrm{ns}}$ & $0,15^{\mathrm{ns}}$ & $-0,03^{\mathrm{ns}}$ \\
\hline $\mathrm{P}-\mathrm{H}_{2} \mathrm{O}$ & $0,47^{\mathrm{ns}}$ & $0,29^{\text {ns }}$ & $0,51^{*}$ & $0,22^{\text {ns }}$ & $-0,03^{\mathrm{ns}}$ & $-0,28^{\mathrm{ns}}$ \\
\hline $\mathrm{P}-\mathrm{Al}$ & $0,30^{\mathrm{ns}}$ & $0,12^{\text {ns }}$ & $0,39^{\text {ns }}$ & $0,36^{\text {ns }}$ & $-0,12^{\mathrm{ns}}$ & $-0,17^{\mathrm{ns}}$ \\
\hline $\mathrm{P}-\mathrm{Fe}$ & $0,19^{\mathrm{ns}}$ & $0,00^{\mathrm{ns}}$ & $0,40^{\mathrm{ns}}$ & $-0,03^{\mathrm{ns}}$ & $0,20^{\mathrm{ns}}$ & $0,34^{\mathrm{ns}}$ \\
\hline $\mathrm{P}-\mathrm{Ca}$ & $0,62^{*}$ & $0,57^{*}$ & $0,68^{*}$ & $-0,09^{\mathrm{ns}}$ & $0,19^{\text {ns }}$ & $-0,06^{\mathrm{ns}}$ \\
\hline Planta ${ }^{(1)}$ & $0,36^{\mathrm{ns}}$ & $0,12^{\mathrm{ns}}$ & $0,43^{\mathrm{ns}}$ & $0,33^{\mathrm{ns}}$ & $-0,14^{\mathrm{ns}}$ & $-0,23^{\mathrm{ns}}$ \\
\hline \multicolumn{7}{|c|}{ Dose de $\mathrm{P}=75$ ou 88 ou $103 \mathrm{mg} \mathrm{dm}^{-3}(\mathrm{n}=12)$} \\
\hline Pi-total & $0,66^{*}$ & $0,62^{*}$ & $0,73^{*}$ & $-0,17^{\mathrm{ns}}$ & $0,30^{\mathrm{ns}}$ & $-0,07^{\mathrm{ns}}$ \\
\hline $\mathrm{P}-\mathrm{H}_{2} \mathrm{O}$ & $0,44^{\mathrm{ns}}$ & $0,08^{\mathrm{ns}}$ & $0,43^{\text {ns }}$ & $0,54^{*}$ & $-0,32^{\mathrm{ns}}$ & $-0,41^{\mathrm{ns}}$ \\
\hline P-Al & $0,57^{*}$ & $0,67^{*}$ & $0,51^{*}$ & $-0,16^{\mathrm{ns}}$ & $0,28^{\mathrm{ns}}$ & $-0,42^{\mathrm{ns}}$ \\
\hline $\mathrm{P}-\mathrm{Fe}$ & $0,27^{\mathrm{ns}}$ & $0,30^{\mathrm{ns}}$ & $0,42^{\text {ns }}$ & $-0,52^{*}$ & $0,62^{*}$ & $0,47^{\mathrm{ns}}$ \\
\hline $\mathrm{P}-\mathrm{Ca}$ & $0,63^{*}$ & $0,59^{*}$ & $0,70^{*}$ & $-0,12^{\mathrm{ns}}$ & $0,21^{\mathrm{ns}}$ & $-0,06^{\mathrm{ns}}$ \\
\hline Planta $^{(1)}$ & $0,42^{\mathrm{ns}}$ & $0,11^{\mathrm{ns}}$ & $0,51^{*}$ & $0,60^{*}$ & $-0,32^{\mathrm{ns}}$ & $-0,48^{*}$ \\
\hline
\end{tabular}

(1) Conteúdo de P na planta (mg/vaso); *Significativo a $5 \%$.

Os teores de P-Fe correlacionaram-se razoavelmente bem com o teor de argila $\left(r=0,62^{*}\right)$ e com o Prem $\left(r=-0,52^{*}\right)$ apenas na presença de adubação fosfatada (Quadro 3), evidenciando que nos solos mais argilosos e com maior capacidade-tampão de fosfato ocorre maior formação de P-Fe, dependendo também dos teores de Fe destes. Souza et al. (2007) verificaram que, à medida que aumentam os teores de $\mathrm{MO}$, gibbsita, argila e os de $\mathrm{Fe}$ e de $\mathrm{Al}$ extraídos tanto com ditionito como com oxalato, aumenta a adsorção de $\mathrm{P}$ e seu teor nas formas ligadas a $\mathrm{Al}$ e $\mathrm{Fe}$.

O P extraído dos solos pela planta correlacionouse $\left(r=0,60^{* *}\right)$ apenas com o Prem na presença da adubação fosfatada (Quadro 3), indicando que a planta recuperou maior proporção da dose de $\mathrm{P}$ aplicada nos solos de menor capacidade-tampão de fosfato, os quais apresentam maiores teores de $\mathrm{P}-\mathrm{H}_{2} \mathrm{O}\left(\mathrm{r}=0,54^{*}\right)$. Sabe-se que solos de CMAP baixa mantêm maiores concentrações de $\mathrm{P}$ na solução do solo em comparação aos de CMAP elevada, principalmente após a aplicação de $\mathrm{P}$ ao solo. Assim, solos com maiores valores de Prem (CMAP baixa) mantêm maiores concentrações de $\mathrm{P}-\mathrm{H}_{2} \mathrm{O}$ no solo e de P na planta (Muniz et al., 1985; Novais \& Smyth, 1999; Moreira et al., 2006).

Os teores de $\mathrm{P}$ extraídos pelos quatro extratores e pela planta apresentaram grande variabilidade entre solos na ausência da adubação fosfatada (Quadro 4), evidenciando que os solos diferem bastante quanto às suas reservas de $\mathrm{P}$ lábil. $\mathrm{O}$ extrator Mehlich-3, seguido da resina de troca iônica mista, foi o que mais extraiu $\mathrm{P}$ em todos os solos.
No grupo de solos mais intemperizados, a quantidade média de $\mathrm{P}$ extraída pelo Bray-1 $\left(28,6 \mathrm{mg} \mathrm{dm}^{-3}\right)$ não diferiu muito da dos demais extratores, porém o comportamento desse extrator foi diferente dentro do grupo de solos menos intemperizados (Quadro 4). Nos solos RR, RL e TX, o Bray-1 extraiu quantidades de $\mathrm{P}$ semelhantes às dos demais extratores, mas nos solos alcalinos e muito ricos em $\mathrm{Ca}^{2+}$ (SX, RY e VX), na ausência de adubação fosfatada, ele extraiu apenas 15, 30 e $29 \%$ do P extraído pelos extratores Mehlich-3, resina e Mehlich-1, respectivamente. Para os mesmos solos, na presença de adubação fosfatada, esses valores foram de 32, 44 e $54 \%$, respectivamente (Quadro 4). $\mathrm{O}$ extrator Bray-1 é composto de $\mathrm{HCl} 0,025 \mathrm{~mol} \mathrm{~L}^{-1}$ $+\mathrm{NH}_{4} \mathrm{~F}$ 0,03 $\mathrm{mol} \mathrm{L}^{-1}$. Nos solos alcalinos, sobretudo naqueles mais argilosos e que têm sua alcalinidade mais tamponada, a pequena acidez do extrator Bray-1 é rapidamente consumida quando este entra em contato com o solo, diminuindo seu poder de extração. Por outro lado, a maior parte do $\mathrm{P}$ dos solos SX, RY e VX é composta de P-Ca e não de P-Al (Quadro 2), que é a forma de $\mathrm{P}$ preferencialmente extraída pelo Bray-1. Além disso, uma parte dos íons F- do extrator Bray-1 deve ter sido consumida pelo excesso de $\mathrm{Ca}^{2+}$ nesses solos (Quadro 1) para formar $\mathrm{CaF}_{2}$, o que também contribui para diminuir o poder de extração do $\mathrm{P}$ do solo pelo Bray-1. Portanto, o extrator Bray-1 não deve ser utilizado em solos alcalinos e ricos em $\mathrm{Ca}$, pois tendem a subestimar o P extraível (Silva \& Raij, 1999; Santos et al., 2008).

$\mathrm{Na}$ ausência da adubação fosfatada, foi verificada correlação elevada entre os teores de $\mathrm{P}$ extraídos dos 
Quadro 4. Teores de P disponível pelos extratores Mehlich-1, resina de troca iônica mista, Mehlich-3 e Bray-1 e de P extraído pela planta em solos representativos do Estado da Paraíba, em função de doses de $\mathbf{P}$ aplicadas

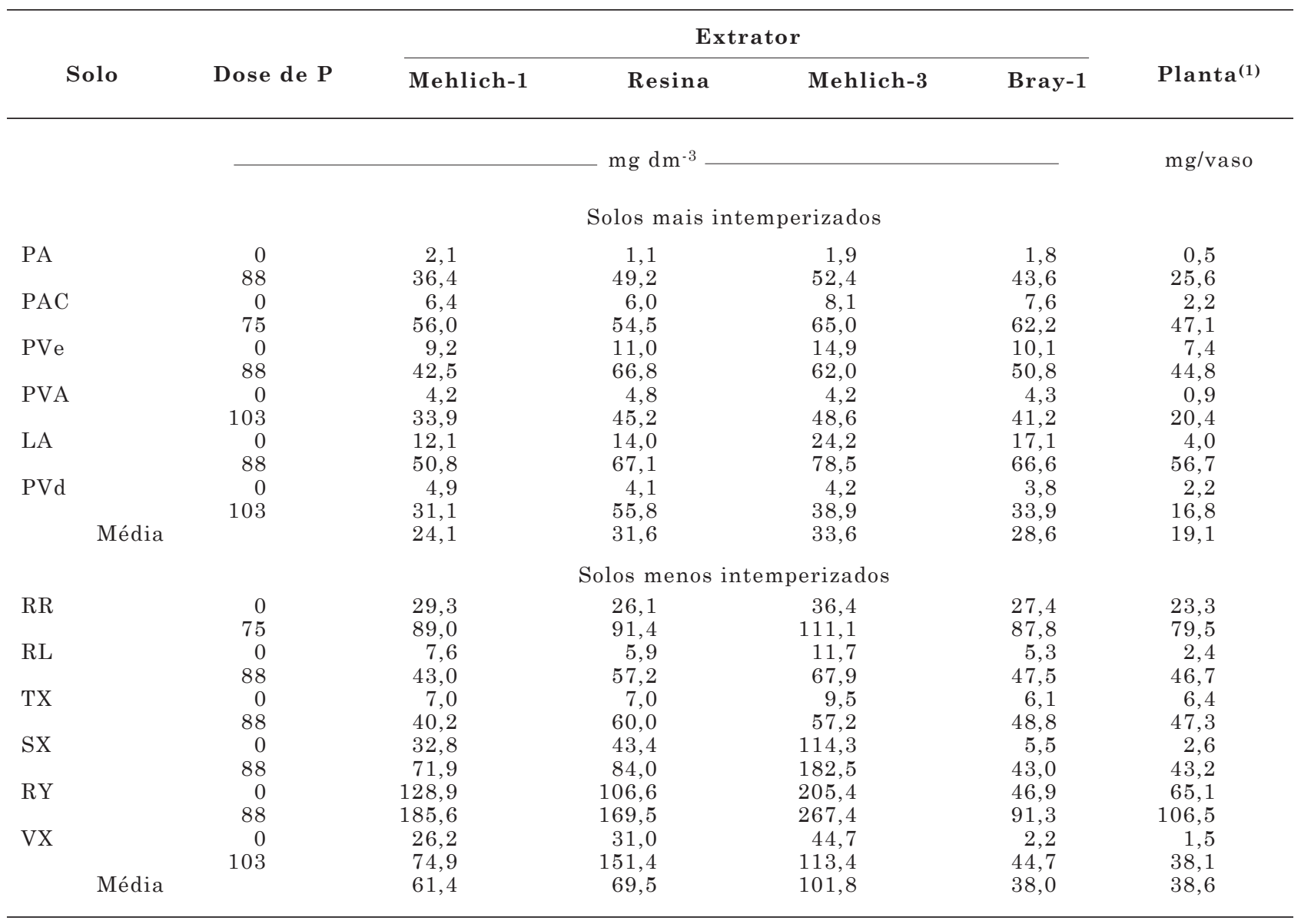

(1)Acúmulo de P na planta (mg vaso-1); ${ }^{*}$ Significativo a $5 \%$.

solos pela planta e os teores de $\mathrm{P}-\mathrm{H}_{2} \mathrm{O}\left(\mathrm{r}=0,98^{* * *}\right)$ e de $\mathrm{P}-\mathrm{Al}\left(\mathrm{r}=0,94^{* * *}\right)$ e uma correlação menor com os teores de P-Ca $\left(r=0,63^{* *}\right)$ e de P-Fe $\left(r=0,59^{* * *}\right)$ (Quadro 5). Quando se adicionou $\mathrm{P}$ aos solos, os teores de $\mathrm{P}$ extraídos pela planta não se correlacionaram mais com as frações P-Al ( $\left.r=0,49^{n s}\right)$ e P-Fe $\left(r=0,16^{n s}\right)$, porém apresentaram correlação elevada com a fração $\mathrm{P}-\mathrm{H}_{2} \mathrm{O}\left(\mathrm{r}=0,89^{*}\right)$ e baixa correlação com a fração P-Ca $\left(r=0,50^{*}\right)$. Assim, o extrator de $\mathrm{P}$ disponível para as plantas mais indicado para esses solos, quando adubado, deverá ser aquele que tiver maior preferência em extrair $\mathrm{P}-\mathrm{H}_{2} \mathrm{O}$ e menor preferência em extrair P-Ca.

Nos tratamentos com ausência de $\mathrm{P}$, a fração $\mathrm{P}$-Fe apresentou baixa correlação com os teores de $\mathrm{P}$ extraídos pelos quatro extratores e pela planta; após a adubação fosfatada, essa correlação foi não significativa (Quadro 5). Isso indica que nos solos do Estado da Paraíba, onde se encontram baixos teores de $\mathrm{Fe}_{2} \mathrm{O}_{3}$ (Brasil, 1972), o Fe não tem papel importante na fixação de P. Por sua vez, a fração $\mathrm{P}-\mathrm{H}_{2} \mathrm{O}$ mostrou correlação elevada com todos os extratores e com a planta, principalmente na ausência de adubação fosfatada (Quadro 5). Embora a fração $\mathrm{P}-\mathrm{H}_{2} \mathrm{O}$ represente menos de $10 \%$ do Pi-total (Quadro 2), esta deve contribuir muito para a absorção de $\mathrm{P}$ pela planta. Na presença de adubação fosfatada, a correlação ainda elevada entre a planta e a fração $\mathrm{P}-\mathrm{H}_{2} \mathrm{O}\left(\mathrm{r}=0,89^{* *}\right)$ indica que parte da dose do $\mathrm{P}$ aplicado aos solos fica prontamente disponível para as plantas, provavelmente devido à baixa CMAP desses solos (Quadro 1), quando comparados a solos de outras regiões do País (Farias et al., 2009a).

Acompanhando a tendência da planta, as quantidades de $\mathrm{P}$ extraídas pelos extratores Mehlich-1, resina e Bray-1 correlacionaram-se mais com as frações $\mathrm{P}-\mathrm{H}_{2} \mathrm{O}$ e $\mathrm{P}-\mathrm{Al}$, ao passo que aquelas extraídas pelo extrator Mehlich-3 correlacionaramse mais com o P-Ca (Quadro 5). Estudando solos da ilha de Fernando de Noronha, Rocha et al. (2005) verificaram que o extrator Mehlich-3 correlacionou- 
Quadro 5. Coeficientes de correlação linear simples entre os teores das frações de $\mathbf{P}$ inorgânico do solo e os teores de $\mathbf{P}$ extraídos do solo por vários extratores e pela planta

\begin{tabular}{|c|c|c|c|c|c|}
\hline Fração de Pi & Mehlich-1 & Resina & Mehlich-3 & Bray-1 & Planta \\
\hline \multicolumn{6}{|c|}{ Todas as doses juntas $(\mathrm{n}=24)$} \\
\hline $\begin{array}{l}\text { Pi-total } \\
\text { P- } \mathrm{H}_{2} \mathrm{O} \\
\text { P-Al } \\
\text { P-Fe } \\
\text { P-Ca } \\
\text { Planta }\end{array}$ & $\begin{array}{l}0,90^{*} \\
0,83^{*} \\
0,79^{*} \\
0,56^{*} \\
0,72^{*} \\
0,91^{*}\end{array}$ & $\begin{array}{l}0,89^{*} \\
0,72^{*} \\
0,91^{*} \\
0,64^{*} \\
0,64^{*} \\
0,85^{*}\end{array}$ & $\begin{array}{l}0,96^{*} \\
0,71^{*} \\
0,71^{*} \\
0,55^{*} \\
0,87^{*} \\
0,81^{*}\end{array}$ & $\begin{array}{l}0,61^{*} \\
0,79^{*} \\
0,86^{*} \\
0,55^{*} \\
0,24^{\mathrm{ns}} \\
0,95^{*}\end{array}$ & $\begin{array}{l}0,73^{*} \\
0,86^{*} \\
0,83^{*} \\
0,56^{*} \\
0,43^{*} \\
\text { - }\end{array}$ \\
\hline \multicolumn{6}{|c|}{ Dose de $\mathrm{P}=0 \mathrm{mg} \mathrm{dm}^{-3}(\mathrm{n}=12)$} \\
\hline $\begin{array}{l}\text { Pi-total } \\
\text { P- } \mathrm{H}_{2} \mathrm{O} \\
\text { P-AI } \\
\text { P-Fe } \\
\text { P-Ca } \\
\text { Planta }\end{array}$ & $\begin{array}{l}0,91^{*} \\
0,98^{*} \\
0,94^{*} \\
0,57^{*} \\
0,83^{*} \\
0,94^{*}\end{array}$ & $\begin{array}{l}0,96^{*} \\
0,94^{*} \\
0,91^{*} \\
0,56^{*} \\
0,90^{*} \\
0,89^{*}\end{array}$ & $\begin{array}{l}0,98^{*} \\
0,88^{*} \\
0,87^{*} \\
0,56^{*} \\
0,95^{*} \\
0,83^{*}\end{array}$ & $\begin{array}{l}0,69^{*} \\
0,90^{*} \\
0,92^{*} \\
0,62^{*} \\
0,52^{\text {ns }} \\
0,95^{*}\end{array}$ & $\begin{array}{l}0,77^{*} \\
0,98^{*} \\
0,94^{*} \\
0,59^{*} \\
0,63^{*} \\
\quad\end{array}$ \\
\hline \multicolumn{6}{|c|}{ Dose de $\mathrm{P}=75$ ou 88 ou $103 \mathrm{mg} \mathrm{dm}^{-3}(\mathrm{n}=12)$} \\
\hline $\begin{array}{l}\text { Pi-total } \\
\text { P- }{ }_{2} \mathrm{O} \\
\text { P-Al } \\
\text { P-Fe } \\
\text { P-Ca } \\
\text { Planta }\end{array}$ & $\begin{array}{l}0,84^{*} \\
0,83^{*} \\
0,70^{*} \\
0,31^{\mathrm{ns}} \\
0,77^{*} \\
0,87^{*}\end{array}$ & $\begin{array}{l}0,85^{*} \\
0,63^{*} \\
0,83^{*} \\
0,40^{\mathrm{ns}} \\
0,75^{*} \\
0,66^{*}\end{array}$ & $\begin{array}{l}0,92^{*} \\
0,68^{*} \\
0,61^{*} \\
0,34^{\mathrm{ns}} \\
0,93^{*} \\
0,76^{*}\end{array}$ & $\begin{array}{l}0,38^{\text {ns }} \\
0,90^{*} \\
0,36^{\text {ns }} \\
0,02^{\text {ns }} \\
0,28^{\text {ns }} \\
0,94^{*}\end{array}$ & $\begin{array}{l}0,59^{*} \\
0,89^{*} \\
0,49^{\text {ns }} \\
0,16^{\text {ns }} \\
0,50^{*} \\
\quad-\end{array}$ \\
\hline
\end{tabular}

(1) Conteúdo de P na planta (mg/vaso); "Significativo a $5 \%$.

se significativamente com as frações consideradas lábeis, ou seja, $\mathrm{P}$ facilmente solúvel, $\mathrm{P}$ inorgânico lábil, $\mathrm{P}$ inorgânico moderadamente lábil, além do P-Fe. Embora o extrator Bray-1 tenha se correlacionado bem $\left(\mathrm{r}=0,94^{* *}\right)$ com o $\mathrm{P}$ absorvido pela planta (Quadro 5), ele extraiu pouco $\mathrm{P}$ nos solos alcalinos e ricos em $\mathrm{Ca}^{2+}$ (Quadro 4), razão pela qual não é adequado recomendá-lo para todos os solos do Estado da Paraíba. Em termos de correlação com a planta e com o P-Ca, os extratores Mehlich-3 e resina não foram muito diferentes (Quadro 5), embora na maioria dos casos o Mehlich-3 tenha extraído mais $\mathrm{P}$ do solo que a resina (Quadro 4). Semelhantemente ao que ocorreu com a planta, a melhor correlação do Mehlich-1 foi com a fração $\mathrm{P}-\mathrm{H}_{2} \mathrm{O}$, de modo que este extrator foi o que melhor se correlacionou com o $\mathrm{P}$ absorvido pela planta (Quadro 5).

Em comparação com a resina, o Mehlich-1 apresentou menor correlação com o P-Ca onde não se aplicou $\mathrm{P}$ e correlação semelhante quando se aplicou esse nutriente (Quadro 5). Fazendo uma análise de correlação considerando apenas os três solos ricos em P-Ca (SX, RY e VX) e as duas doses de $\mathrm{P}$ juntas, a correlação entre o $\mathrm{P}$ absorvido pela planta e o $\mathrm{P}$ determinado pelo Mehlich-1 $\left(r=0,99^{* *}\right)$ foi ainda maior que aquela entre o conteúdo de $\mathrm{P}$ na planta e o $\mathrm{P}$ extraído pela resina $\left(r=0,85^{* *}\right)$. A correlação significativa entre P-Ca e a resina de troca iônica mista pode ser explicada pela extração de $\mathrm{Ca}^{2+}$ pela resina catiônica, o que favorece a solubilização de fosfato de $\mathrm{Ca}$ e a consequente liberação de $\mathrm{P}$ para a solução de equilíbrio no processo de extração com este extrator.

A eficiência do Mehlich-1, bem como da resina e do Bray-1, também foi constatada por Holanda et al. (1995), que os testaram em um Latossolo VermelhoAmarelo do Estado de São Paulo e verificaram que o P disponível avaliado pelo extrator Mehlich-1 apresentou correlação elevada com a produção de matéria seca e com o P acumulado na planta. A grande diferença entre esses extratores parece ter sido em relação à quantidade de $\mathrm{P}$ extraída no solo VX após a realização da adubação fosfatada, em que a resina extraiu o dobro do $\mathrm{P}$ extraído pelo Mehlich-1. Neste solo, a maior parte da dose de $\mathrm{P}$ aplicada formou P-Al (Quadro 2), que foi a fração de Pi preferencialmente extraída pela resina $(\mathrm{r}=$ $\left.0,83^{*}\right)$ na presença de adubação fosfatada (Quadro 5). Diante do exposto, sugere-se a realização de outros estudos, semelhantes a este, para avaliar a eficiência dos extratores Mehlich-1 e resina, porém utilizando apenas solos alcalinos e ricos em $\mathrm{Ca}^{2+}$, os quais são comuns no semiárido nordestino.

\section{CONCLUSÕES}

1. Nos solos mais intemperizados e naqueles menos intemperizados contendo valores de $\mathrm{pH}$ e teores de $\mathrm{Ca}^{2+}$ mais baixos, a maioria do Pi ocorreu nas formas de $\mathrm{P}-\mathrm{Al}$ e de $\mathrm{P}-\mathrm{Fe}$, enquanto nos solos alcalinos com teores muito elevados de $\mathrm{Ca}^{2+}$ o Pi ocorreu principalmente na forma de P-Ca. 
2. Acompanhando a tendência da planta, os teores de $\mathrm{P}$ extraídos pelo Mehlich-1, resina de troca iônica mista e Bray-1 correlacionaram-se mais com as frações $\mathrm{P}-\mathrm{H}_{2} \mathrm{O}$ e $\mathrm{P}-\mathrm{Al}$, e aquelas extraídas pelo extrator Mehlich-3, mais com o P-Ca.

3. Mehlich-1 e Bray-1 foram os extratores que mais se correlacionaram com a planta quanto à absorção de $\mathrm{P}$ nos solos estudados. O Bray-1 extraiu pouco $\mathrm{P}$ em solos ricos em $\mathrm{Ca}$ e com $\mathrm{pH}$ elevado.

4. De maneira geral, os teores de $\mathrm{P}$ quantificados pelo Mehlich-1 foram semelhantes aos extraídos pela resina de troca iônica mista, mesmo nos solos ricos em $\mathrm{Ca}$ e com $\mathrm{pH}$ elevado.

\section{LITERATURA CITADA}

ALVAREZ V., V.H.; NOVAIS, R.F.; DIAS, L.E. \& OLIVEIRA, J.A. Determinação e uso do fósforo remanescente. B. Inf. SBCS, 25:27-32, 2000.

BAHIA FILHO, A.F.C.; BRAGA, J.M.; RIBEIRO, A.C. \& NOVAIS, R.F. Sensibilidade de extratores químicos à capacidade tampão de fósforo R. Bras. Ci. Solo, 7:243-249, 1983.

BRAGA, J.M. \& DEFELIPO, B.V. Determinação espectrofotométrica de fósforo em extratos de solo e material vegetal. R. Ceres, 21:73-85, 1974.

BRASIL. SUDENE. Levantamento exploratório-reconhecimento de solos do estado da Paraíba. Rio de Janeiro, 1972. 683p. (Boletim Técnico,15; SUDENE. Serie Pedológica, 8)

BRAY, R.H., \& KURTZ, L.T. Determination of total, organic, and available forms of phosphorus in soils. Soil Sci., 59:3945, 1945.

CHANG, S.C. \& JACKSON, M.L. Fractionation of soil phosphorus. Soil Sci., 84:133-144, 1957.

EMPRESA BRASILEIRA DE PESQUISA AGROPECUÁRIA EMBRAPA. Centro Nacional de Pesquisa Agropecuária. Manual de métodos de análise de solo. Rio de Janeiro, 1997. 212p.

EMPRESA BRASILEIRA DE PESQUISA AGROPECUÁRIA EMBRAPA. Centro Nacional de Pesquisa Agropecuária. Sistema brasileiro de classificação de solos. 2.ed. Rio de Janeiro, 2006. 306p.

FARIAS, D.R.; OLIVEIRA, F.H.T.; SANTOS, D.; ARRUDA, J.A.; HOFFMANN, R.B. \& NOVAIS, R.F. Fósforo em solos representativos do Estado da Paraíba. I. Isotermas de adsorção e medidas do fator capacidade de fósforo. R. Bras. Ci. Solo, 33:623-632, 2009a.

FARIAS, D.R.; OLIVEIRA, F.H.T.; SANTOS, D.; ARRUDA, J.A.; HOFFMANN, R.B. \& NOVAIS, R.F. Fósforo em solos representativos do Estado da Paraíba. II. Disponibilidade de fósforo para plantas de milho. R. Bras. Ci. Solo, 33:633646,2009 b.
GATIBONI, L.C.; KAMINSKI, J.; RHEINHEIMER, D. S. \& FLORES, J.P.C. Biodisponibilidade de formas de fósforo acumuladas em solo sob sistema plantio direto. R. Bras. Ci. Solo, 31:691-699, 2007.

HOLANDA, J.S.; BRASIL, E.C.; SALVIANO, A.A.C.; CARVALHO, M.C.S.; RODRIGUES, M.R.L. \& MALAVOLTA, E. Eficiência de extratores de fósforo para um solo adubado com fosfatos e cultivado com arroz. Sci. Agric., 52:561-568, 1995.

KUO, S. Phosphorus. In: BIGHAM, J.M. Methods of soil analysis: Chemical methods. Madison, Soil Science Society America/ American Society of Agronomy, 1996. Part. 3. p.869-919.

MEHLICH, A. Determination of $\mathrm{P}, \mathrm{Ca}, \mathrm{Mg}, \mathrm{K}, \mathrm{Na}$ and $\mathrm{NH}_{4}$ by North Carolina soil testing laboratories. Raleigh, University of North Carolina, 1953. 8p.

MEHLICH, A. Mehlich-3 soil test extractant: A modification of Mehlich-2 extractant. Comm. Soil Sci. Plant Anal., 15:14091416, 1984.

MOREIRA, A. \& MALAVOLTA, E. Fontes, doses e extratores de fósforo em alfafa e centrosema. Pesq. Agropec. Bras.,. 36:1519-1527, 2001.

MOREIRA, F.L.M.; MOTA, F.O.B.; CLEMENTE, C.A.; AZEVEDO, B.M. \& BOMFIM, G.V. Adsorção de fósforo em solos do Estado do Ceará. R. Ci. Agron., 37:7-12, 2006.

MUNIZ, A.S.; NOVAIS, R.F.; BARROS, N.F. \& NEVES, J.C.L. Níveis críticos de fósforo na parte aérea da soja como variável do fator capacidade de fósforo do solo. R. Bras. Ci. Solo, 9:237-243, 1985.

NOVAIS, R.F. \& KAMPRATH, E.J. Phosphorus supplying capacities of previously heavily fertilized soils. Soil Sci. Soc. Am. J., 42:931-935, 1978.

NOVAIS, R.F. \& SMYTH, T.J. Fósforo em solo e planta em condições tropicais. Viçosa, MG, Universidade Federal de Viçosa, 1999. 399p.

NOVELINO, J.O.; NOVAIS, R.F.; NEVES, J.C.L.; COSTA, L.M. \& BARROS, N.F. Solubilização de fosfato de Araxá, em diferentes tempos de incubação, com amostras de cinco Latossolos, na presença e na ausência de calagem. R. Bras. Ci. Solo, 9:13-22, 1985.

OLIVEIRA, F.H.T.; LEAL, J.V.; SANTOS, D.J.; FARIAS, D.R. \& ARRUDA, J.A. Banco de solos representativos do Estado da Paraíba. In: REUNIÃO BRASILEIRA DE MANEJO E CONSERVAÇÃO DO SOLO E DA ÁGUA, 16., Aracaju, 2006. Anais... Aracaju, Sociedade Brasileira de Ciência do Solo, 2006. CD ROM.

RAIJ, B.van; ANDRADE, J.C.; CANTARELLA, H. \& QUAGGIO, J.A. Análise química para avaliação da fertilidade de solos tropicais. Campinas, Instituto Agronômico de Campinas, 2001. 285p.

RANNO, S.K.; SILVA, L.S. \& MALLMANN, F.J.K. Fracionamento do fósforo inorgânico em solos de várzea do Rio Grande do Sul. R. Bras. Agroci., 13:47-54, 2007.

RIBEIRO, A.C.; GUIMARÃES, P.T.G. \& ALVAREZ V., V.H., eds. Recomendações para o uso de corretivos e fertilizantes em Minas Gerais. Viçosa, MG, CFSEMG, 1999. 359p. 
ROCHA, A.T.; DUDA, G.P.; NASCIMENTO, C.W.A. \& RIBEIRO, M.R. Fracionamento do fósforo e avaliação de extratores do P-disponível em solos da Ilha de Fernando de Noronha. R. Bras. Eng. Agríc. Amb., 9:178-184, 2005.

SANTOS, D.R.; GATIBONI, L.C. \& KAMINSKI, J. Fatores que afetam a disponibilidade do fósforo e o manejo da adubação fosfatada em solos sob sistema plantio direto. Ci. Rural, 38:576-586, 2008.

SILVA, F.C. \& RAIJ, B.van. Disponibilidade de fósforo em solos avaliada por diferentes extratores. Pesq. Agropec. Bras., 34:267-288, 1999.

SILVA, M.A.; NÓBREGA, J.C.A.; CURI, N.; SIQUEIRA, J.O.; MARQUES, J.J.G. \& MOTTA, P.E.F. Frações de fósforo em Latossolos. Pesq. Agropec. Bras., 38:1197-1207, 2003.
SILVEIRA, M.M.L.; ARAÚJO, M.S.B. \& SAMPAIO, E.V.S.B. Distribuição de fósforo em diferentes ordens de solo do semi-árido da Paraíba e de Pernambuco. R. Bras. Ci. Solo, 30:281-291, 2006.

SOUZA, R.F.; FRAQUIN, V.; ANDRADE, A.T. \& TORRES, P.R.F. Formas de fósforo em solos sob influência da calagem e adubação orgânica. R. Bras. Ci. Solo, 31:1535-1544, 2007.

TEDESCO, M.J.; GIANELLO, C.; BISSANI, C.A.; BOHNEN, H. \& VOLKWEISS, S.J. Análises de solos, plantas e outros materiais. 2.ed. Porto Alegre, Universidade Federal do Rio Grande do Sul, 1995. 174p. (Boletim Técnico, 5) 
